\title{
O PERFIL DO EGRESSO DO PROCESSO DE FORMAÇÃO NO ENSINO MÉDIO BRASILEIRO: ENTRE ÓTICAS LEGAIS E IMPACTOS SOBRE A SOCIEDADE
}

http://dx.doi.org/10.5902/2318133863573

\author{
Kenia Kodel Cox ${ }^{1}$ \\ Robelius De-Bortoli²
}

\section{Resumo}

Com este trabalho objetivou-se verificar se o perfil idealizado, pelas bases legais, para o egresso do ensino médio é mantido quando contraposto a indicadores de monitoramento dos resultados deste processo de formação escolar sobre a sociedade. Para identificação do perfil em estudo foi efetuada a análise de conteúdo de leis de bases e de diretrizes curriculares de 13 unidades territoriais do país, seguida pela contraposição do resultado desta a dados diagnósticos de ensino, empregabilidade, matrícula e conclusão no ensino superior. Dos quatro elementos destacados, a partir da análise das bases legais, para composição do perfil em estudo, dois preservaram, ao serem validados a partir da correlação com indicadores de monitoramento: 'continuidade dos estudos' e 'fundamentação científico-tecnológica'. Este trabalho sinaliza a necessidade de aprofundamento de estudos sobre a 'preparação para o trabalho' e 'participação em sociedade' no processo de formação no ensino médio.

Palavras-chave: ensino médio, análise de conteúdo, perfil de egresso, plano estadual de educação, administração da educação.

\section{THE PROFILE OF THE GRADUATED FROM THE TRAINING PROCESSIN BRAZILIAN HIGH SCHOOL: BETWEEN THE LEGAL OPTICS AND IMPACTS ON SOCIETY}

\begin{abstract}
This work aims to verify if the profile idealized, by the legal bases, for the Brazilian students who finished high school, is maintained when confronted to indicators for monitoring the results of this process of school education on society. To identify the profile under study, the content analysis of basic laws and of the curricular guidelines of 13 territorial units of the country was carried out, followed by the comparison of its results with diagnostic data on teaching, employability, enrollment and completion in Brazilian Higher Education. Of the 4 elements highlighted, from the analysis of the basic laws, for the composition of the profile under study, 2 were preserved, when they were validated by the correlation with monitoring indicators: 'continuity of studies' and 'scientifictechnological foundation'. This work signals the need for deepen studies on preparation for work and about participation in society in secondary education in Brazil.

Key-words: high school; content analysis; egress profile; state education plan; education administration.
\end{abstract}

\footnotetext{
${ }^{1}$ Universidade Federal de Sergipe, Brasil. E-mail: kenia@dcomp.ufs.br.

2 Universidade Federal de Sergipe, Brasil. E-mail: robelius@yahoo.com.br. 


\section{Introdução}

A educação escolar brasileira compõe-se da educação básica, formada pela $\triangle$ educação infantil, ensino fundamental e ensino médio, educação superior. A - duração do ensino fundamental é de nove anos distribuídos em anos iniciais e anos finais. $O$ ensino médio tem duração de três anos e culmina com a emissão do certificado de ensino médio. A partir da educação superior é possível a obtenção do diploma de nível superior, necessário para o exercício de algumas profissões.

A LDB é complementada pelos parâmetros curriculares nacionais, os quais visam a difundir os princípios da reforma curricular propostos pela LDB e orientar o professor na busca por metodologias de ensino. Os projetos pedagógicos das instituições de educação infantil, segundo parâmetros nacionais de qualidade para a educação infantil (2006), devem ser orientados por princípios éticos, políticos e estéticos. No ensino fundamental, de acordo com a LDB, o objetivo é o de propiciar a formação básica para a cidadania, oportunizando na escola condições de aprendizagem. Para o ensino médio a LDB reservou uma educação voltada para integrações: com a sociedade, consigo mesmo, com o mundo do trabalho e com o futuro.

Além da LDB também servem de base legal para a educação básica as diretrizes curriculares nacionais gerais para a educação básica e as diretrizes curriculares nacionais para o ensino médio, as quais sistematizam princípios da LDB e subsidiam projetos políticos escolares e orientam cursos de formação docente.

Figura 1 -

Fundamentos norteadores da educação básica do Brasil.

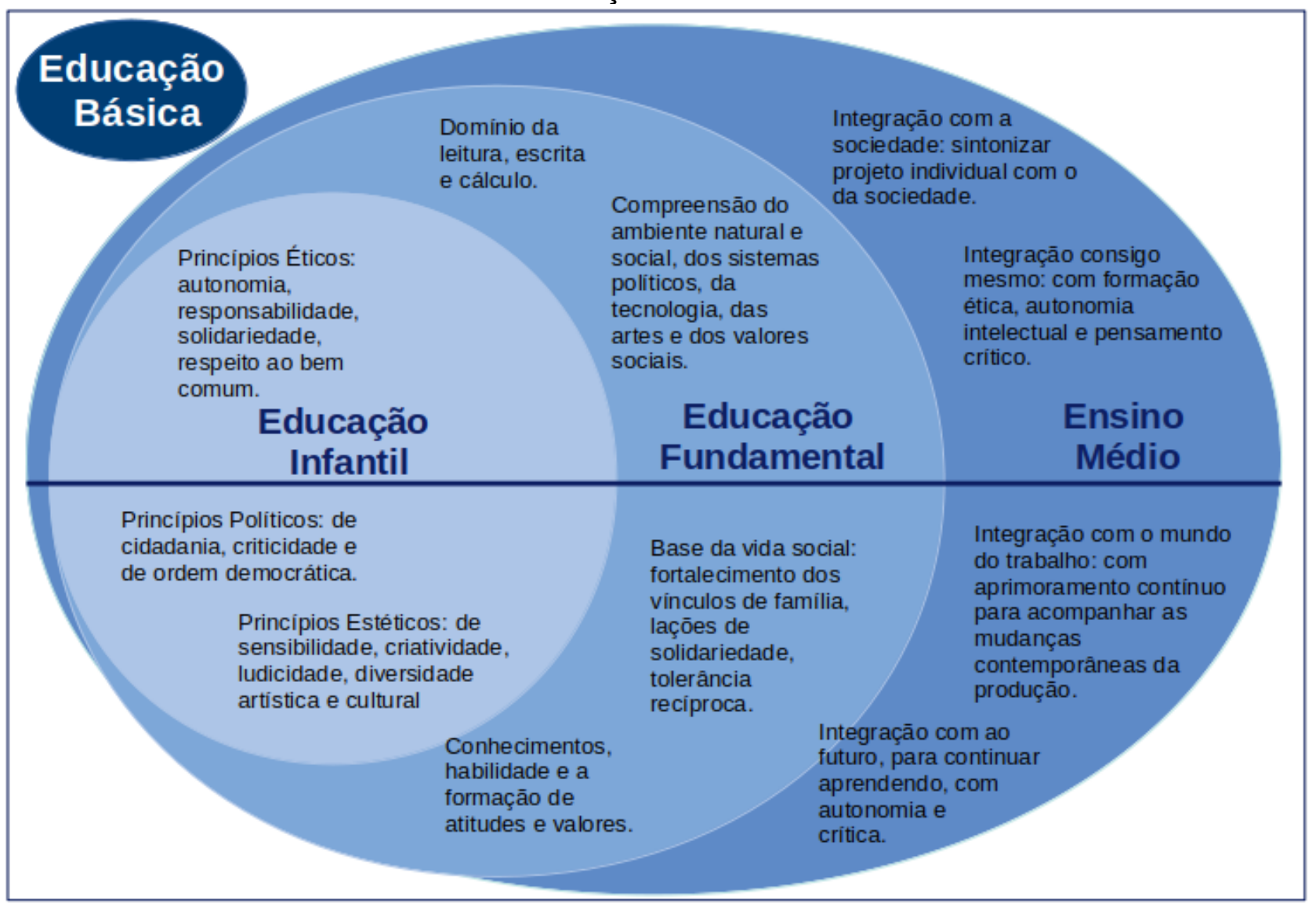

Fonte: autores. 
As DCNs, por sua vez, são completadas por orientações curriculares dos Estados e do Distrito Federal, as quais descrevem como implantar as citadas diretrizes. Estas orientações curriculares estaduais foram elaboradas em atendimento ao art. 26 da LDB, que determina que os currículos devem ser compostos por base nacional comum e parte diversificada conforme especificidade dos Estados.

Para avaliar a Educação Básica do Brasil há o Sistema de Avaliação da Educação Básica - Saeb -, de responsabilidade do Inep, que explora as habilidades dos alunos de leitura em Língua Portuguesa e de resolução de problemas em Matemática, Ciências Humanas e Ciências da Natureza. A partir do desempenho no Saeb é definido o Índice de Desenvolvimento da Educação Básica - Ideb

Concluída a educação básica o egresso do ensino médio, busca colocar-se no mundo do trabalho ou ingressar no ensino superior visando a exercer uma profissão. e a ação destes jovens, seja a partir do ensino médio, ou após a graduação, afeta-os, bem como afeta a qualidade dos produtos e serviços prestados à sociedade, bem como a economia nacional.

Para monitoramento destes processos de acesso ao Ensino Superior ou ao mundo do trabalho dispõe-se de ferramentas como Sinopse Estatística da Educação Superior, pela qual são analisados dados de instituições de ensino, cursos de graduação, processos seletivos, matrícula e concluintes, e a Pesquisa Nacional por Amostra de Domicílio Contínua, por meio da qual se acompanha a força de trabalho do Brasil e outros dados necessários para o estudo socioeconômico do país (IBGE, 2019).

Considerando a relação entre as formações de níveis médio e superior para o atendimento das demandas da sociedade e os impactos dos bens e serviços resultantes da ação profissional dos egressos destes níveis de ensino sobre a qualidade de vida da população e sobre a economia do país, pensou-se em verificar se o perfil idealizado para o egresso do ensino médio, e expresso nas bases legais, é mantido quando contraposto a indicadores de monitoramento dos resultados deste processo de formação escolar sobre a sociedade.

\section{Metodologia}

Para identificação do perfil do egresso foi efetuada a contraposição das prescrições legais - de base e complementares, aos indicadores de monitoramento de empregabilidade e de ingresso no ensino superior brasileiro. Para investigação das bases legais e complementares foi aplicada análise de conteúdo (Bardin, 2016).

$\mathrm{Na}$ etapa de pré-análise ocorreu a seleção de documentos, formulação de hipóteses e definição dos indicadores que oportunizaram a discussão dos resultados e foram considerados a LDB, as DCNs e as orientações curriculares de treze unidades territoriais brasileiras 
Figura 2 -

Fluxo metodológico para identificar perfil do egresso de ensino médio.

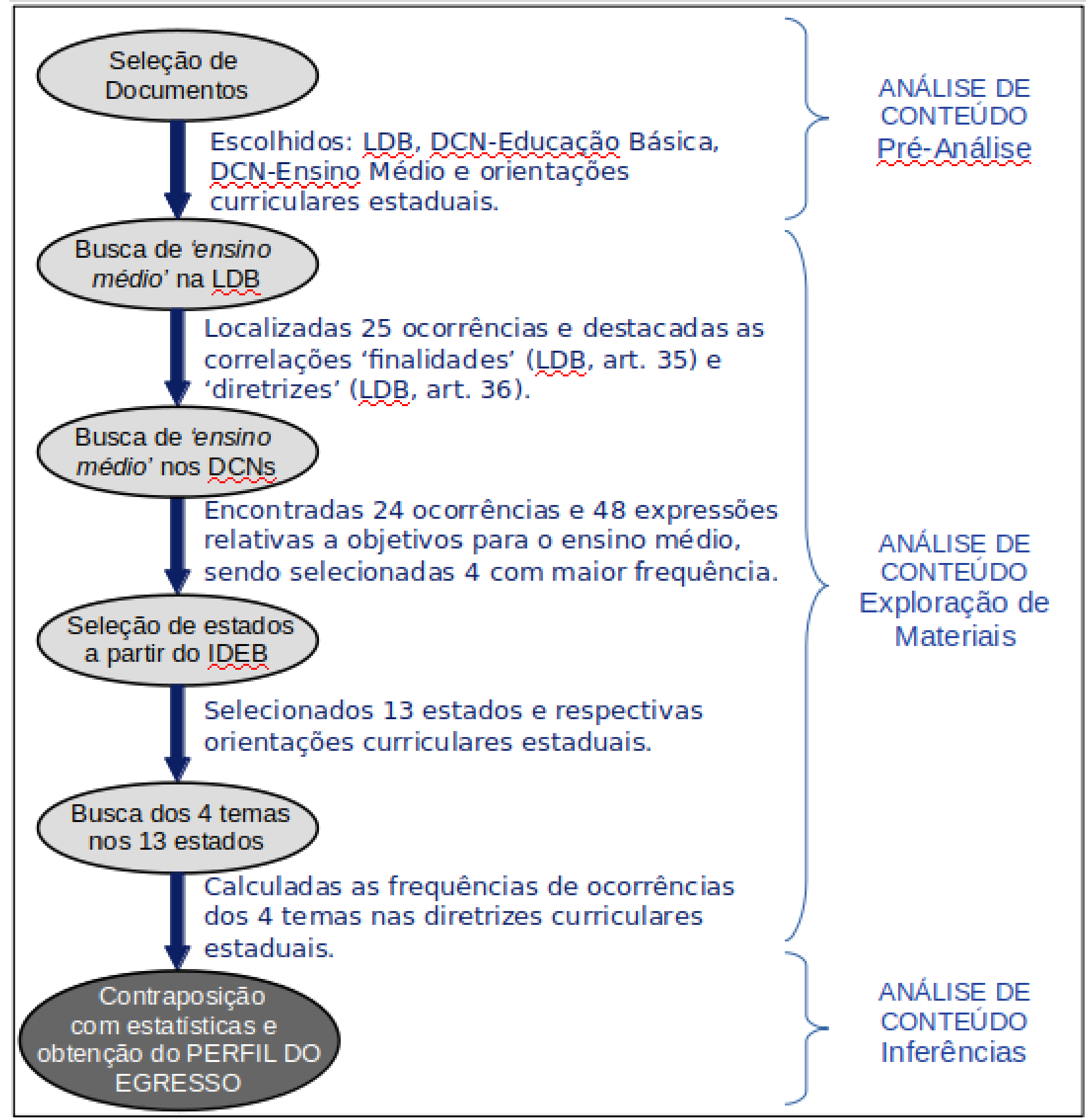

Fonte: autores.

Durante a fase de exploração do material foram delineadas duas principais unidades de análise: registro e contexto. Assim, usando 'ensino médio' como unidade de registro e a LDB como unidade de contexto, foram identificadas 25 ocorrências, apresentando correlação com: incumbência prioritária dos Estados, composição da educação básica, duração, finalidades, diretrizes, composição curricular. A partir desta concluiu-se que as finalidades (LDB, art. 35) e as diretrizes (LDB, art. 36) são as principais fontes de novas unidades de registros, úteis ao delineamento do perfil idealizado para o egresso do ensino médio, pois encerram objetivos deste processo de formação. 
$\mathrm{Na}$ análise das DCNS foram observadas 20 e 24 ocorrências da unidade de registro 'ensino médio', respectivamente. A partir da investigação de contingências em que a expressão foi localizada alcançou-se 48 expressões que definem objetivos para 0 ensino médio, dos quais quatro expressões que se destacaram quantitativamente.

Ainda na fase de exploração, visando a selecionar bases legais complementares, foi efetuada a busca pelas quatro palavras-chaves destacadas em treze unidades de contexto selecionadas a partir do resultado do Ideb (Inep, 2017) sendo quatro unidades territoriais brasileiras com melhor desempenho no índice dentre escolas públicas; quatro dentre escolas particulares e quatro unidades territoriais com menores notas no Ideb dentre unidades escolares do setor público e quatro de natureza privada.

$\mathrm{Na}$ busca pelas bases complementares - orientações curriculares estaduais observou-se que não existe uma uniformização destas, não foram elaborados no mesmo espaço temporal, algumas são específicos a determinadas matérias de ensino, outras voltam-se para todo o ensino básico e apresentam nomenclaturas diversas.

Ainda na segunda fase da análise de conteúdo - exploração de materiais - foram efetuadas buscas nas orientações curriculares estaduais pelas quatro palavras-chaves resultantes das correlações observadas nas bases legais. Um dos temas pesquisados, por exemplo, foi 'continuidade dos estudos'. Para tanto fez-se a busca pela palavra 'estudo' e, em seguida, analisou-se se no contexto estava relacionado à prosseguimento ou continuidade, ou outro sinônimo.

$\mathrm{Na}$ exploração das orientações do Estado da Bahia, por exemplo, foi localizado: "Muitas vezes, o desafio é entendido pelos sistemas de ensino como sendo da necessidade de organizar um currículo que seja capaz de [...] formar a continuidade dos estudos no Ensino Superior" (Bahia, 2015, p. 12) e esta ocorrência foi computada para análise. Já na base complementar relativa ao Estado do Pará foi encontrada: "Na atualidade, muitos estudos são realizados no sentido de pensar a infância como sujeitos sociais" (Pará, 2010, p. 28) e esta não foi considerada por não ter correlação com continuidade.

Então iniciou-se a terceira etapa com a inferência dos resultados a partir da contraposição dos dados obtidos no processo de exploração das bases legais e complementares aos indicadores Ideb, Pnad Contínua, ingresso no ensino superior brasileiros e conclusão da graduação com vistas à acarear o perfil idealizado pelas bases legais da educação a indicadores de monitoramento efetivos.

\section{Resultados}

Um total de 48 expressões foram localizadas nas unidades de contexto correlacionadas a 'ensino médio' na análise de conteúdo, usadas para descreverem objetivos ou metas para este nível de ensino. As ocorrências destas, em sua maioria, nas bases legais, são 1 ou 2; destacando-se 10 com maior frequência. 
Figura 3 -

Número de ocorrências dos registros de unidades nas bases legais.

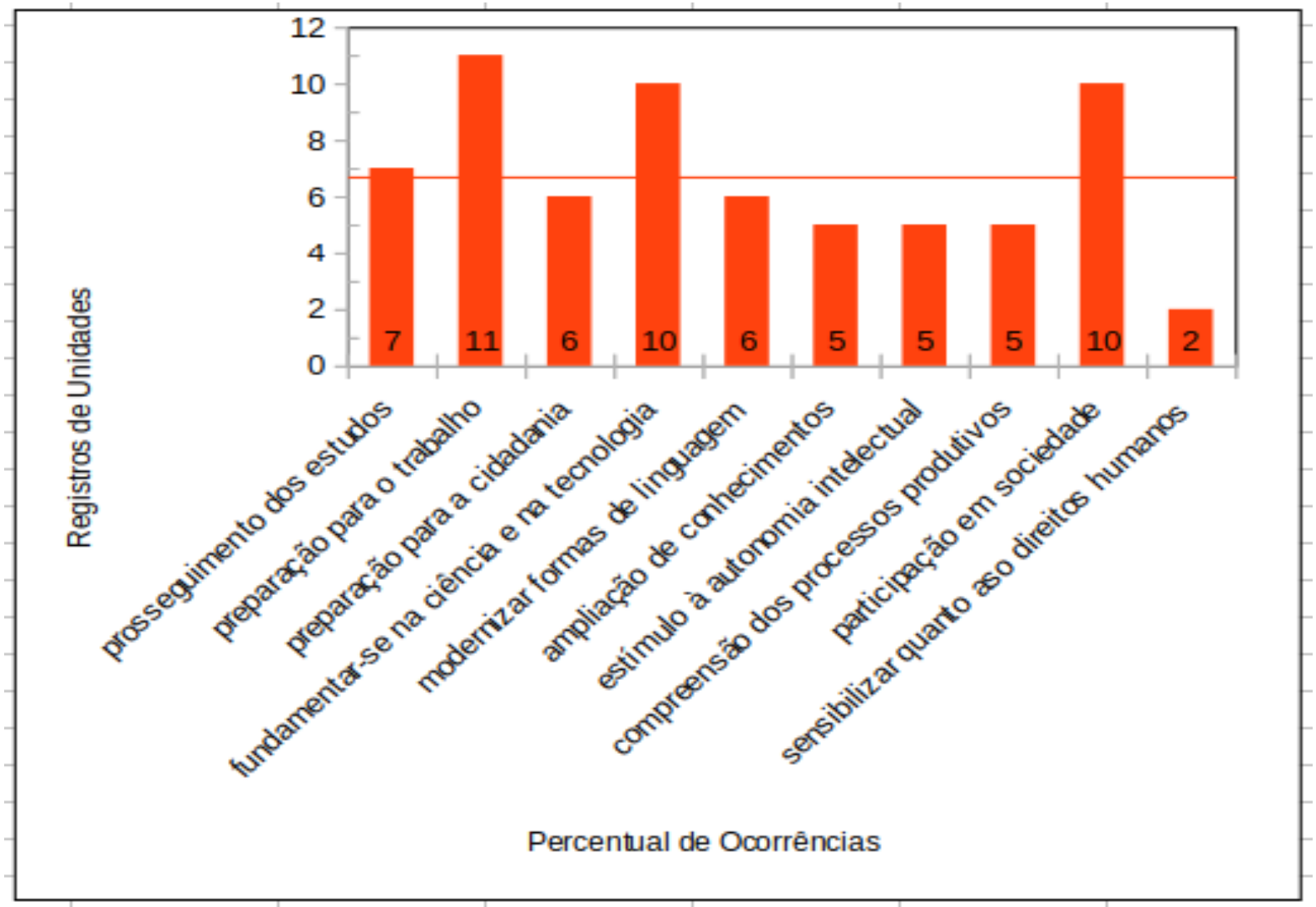

Fonte: autores.

Dos 10 temas foram selecionados quatro devido ao fato de seus números de ocorrências serem acima da média 6,7: 'prosseguimento dos estudos' - 7 ocorrências, 'preparação para o trabalho' - 11, 'fundamentar-se na ciência e na tecnologia' - 10 e 'participação em sociedade' - 10.

Buscando compreender o tratamento dado às expressões destacadas nas orientações curriculares estaduais foram selecionados Estados conforme seus resultados no Ideb: quatro com piores desempenho no Ideb em escolas públicas: Bahia, Pará, Amapá e Paraíba e os quatro melhores: São Paulo, Rio Grande do Norte, Pernambuco e Espírito Santo. 
Figura 4 -

Resultado do Ideb 2017) das escolas públicas do Brasil.

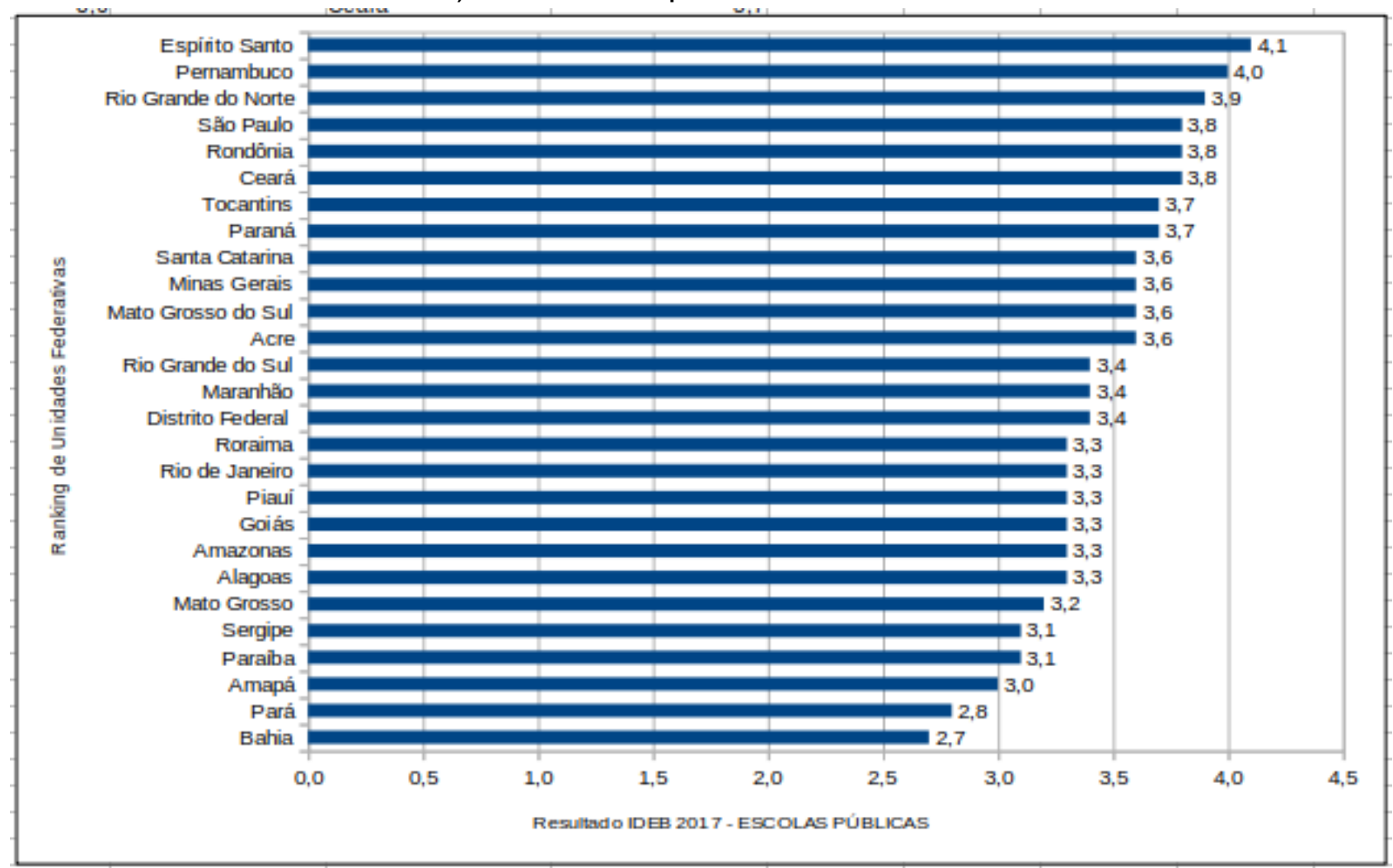

Fonte: autores.

Figura 5 -

Resultado Ideb 2017 das escolas particulares do Brasil.

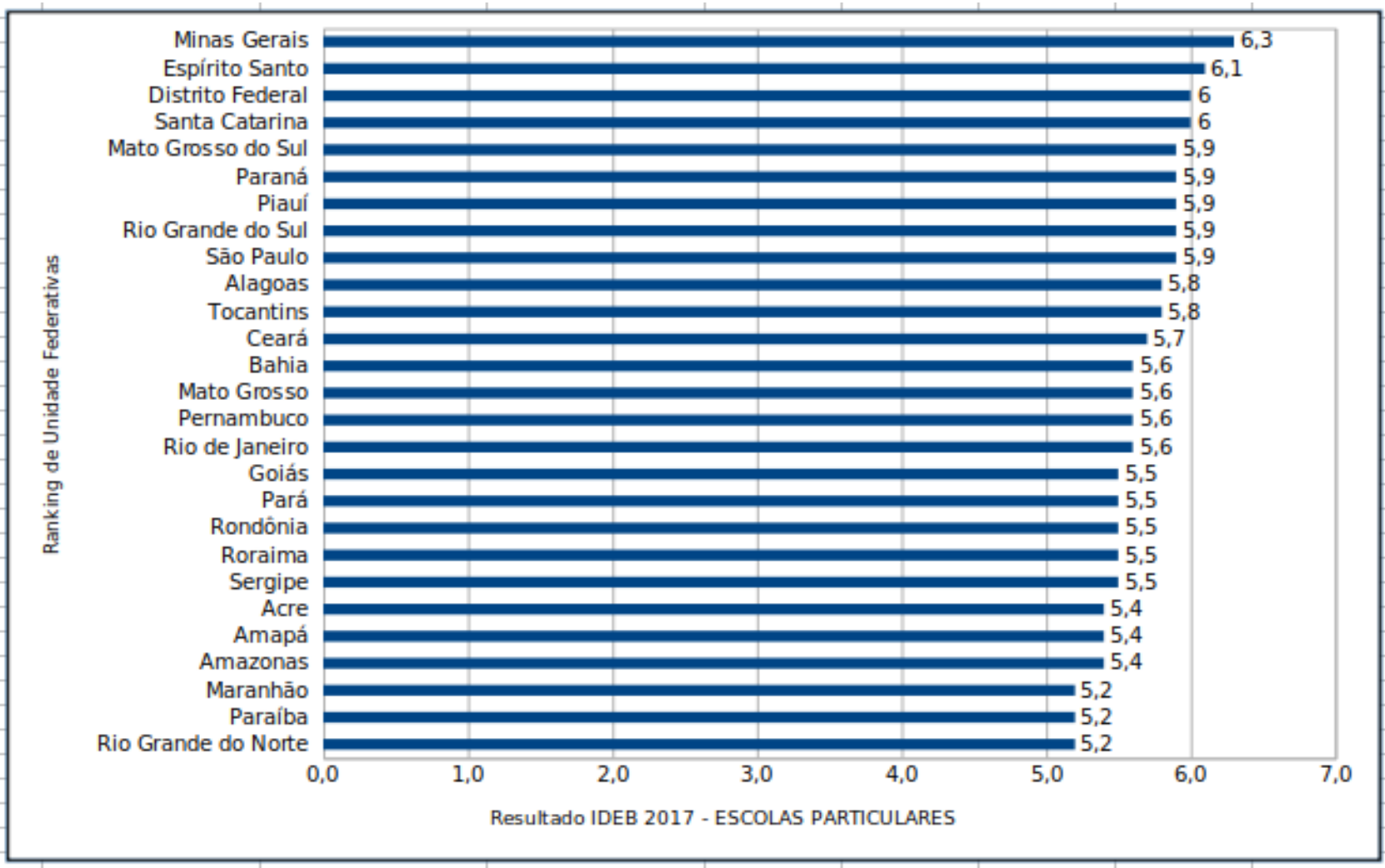

Fonte: autores.

Santa Maria

v. 10

ก. 19

e63573, p. 1-17 
Já os quatro com piores desempenho no Ideb 2017 em escolas particulares foram Maranhão, Paraíba, Rio Grande do Norte e Acre. Os quatro melhores são Distrito Federal, Santa Catarina, Espírito Santo e Minas Gerais.

Assim, tem-se treze Estados a pesquisar já que três destes - PB, RN e ES - são elencados em duas categorias. Então foi efetuada a busca das diretrizes curriculares das unidades territoriais selecionadas e iniciada a exploração das bases complementares, visando a identificar a frequência de ocorrências das palavras-chaves resultantes da análise das bases legais.

Quadro 1 -

Número de ocorrências de registros de unidades selecionados nas bases curriculares estaduais da amostra.

\begin{tabular}{|c|c|c|c|c|c|c|}
\hline \multirow{2}{*}{\multicolumn{3}{|c|}{$\begin{array}{l}\text { Unidades federativas do Brasil } \\
\text { classificadas conforme Ideb } \\
2017 \text { - ensino médio, e } \\
\text { categorizadas por escolas } \\
\text { públicas e particulares }\end{array}$}} & \multicolumn{4}{|c|}{ Ocorrências de unidades de registro } \\
\hline & & & \multirow{2}{*}{$\begin{array}{c}\text { Prossegui- } \\
\text { mento dos } \\
\text { estudos } \\
11\end{array}$} & \multirow{2}{*}{$\begin{array}{c}\text { Preparação } \\
\text { para o } \\
\text { trabalho }\end{array}$} & \multirow{2}{*}{$\begin{array}{c}\text { Fundamentar- } \\
\text { se em ciência } \\
\text { e tecnologia }\end{array}$} & \multirow{2}{*}{ 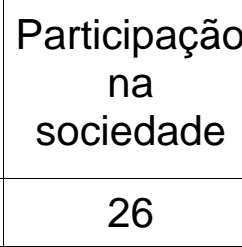 } \\
\hline \multirow{8}{*}{ 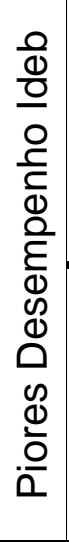 } & \multirow{4}{*}{$\begin{array}{l}\frac{\mathscr{0}}{0} \\
\frac{.0}{2} \\
\frac{0}{2}\end{array}$} & Bahia & & & & \\
\hline & & Pará & 8 & 21 & 24 & 14 \\
\hline & & Amapá & 3 & 6 & 7 & 4 \\
\hline & & Paraíba & 3 & 23 & 23 & 10 \\
\hline & \multirow{4}{*}{ 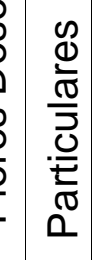 } & Maranhão & 2 & 8 & 15 & 27 \\
\hline & & Paraíba & 3 & 23 & 23 & 10 \\
\hline & & Rio Grande do Norte & 1 & 3 & 10 & 2 \\
\hline & & Acre & 3 & 9 & 14 & 22 \\
\hline \multirow{8}{*}{ 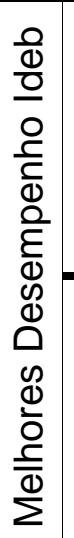 } & \multirow{4}{*}{ 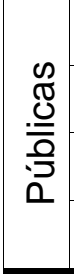 } & São Paulo & 0 & 19 & 53 & 11 \\
\hline & & Rio Grande do Norte & 1 & 3 & 10 & 2 \\
\hline & & Pernambuco & 3 & 9 & 10 & 7 \\
\hline & & Espírito Santo & 1 & 18 & 25 & 14 \\
\hline & \multirow{4}{*}{ 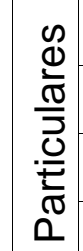 } & Distrito Federal & 5 & 14 & 51 & 14 \\
\hline & & Espírito Santo & 1 & 18 & 25 & 14 \\
\hline & & Santa Catarina & 8 & 13 & 10 & 8 \\
\hline & & Minas Gerais & 1 & 5 & 17 & 4 \\
\hline
\end{tabular}

Fonte: autores.

Dado que o desempenho no Ideb é indicador de diagnóstico da educação básica, para verificar a existência de relação entre este e as expressões-chave resultantes da análise de conteúdo das bases legais foram efetuadas as somas das ocorrências de cada uma das quatro expressões-chave conforme o desempenho Ideb 2017, obtendo-se oito valores: quatro para as escolas de piores desempenhos e quatro para as de melhores 
desempenhos, possibilitando o comparativo entre estas sendo destacado o 'fundamentarse na ciência e tecnologia', e do qual vale investigar a contribuição de cada estado da amostra no cômputo do número de ocorrências final.

Figura 6 -

Comparativo entre escolas de melhores e as de piores desempenho no Ideb 2017 quanto às ocorrências dos registros de unidades selecionados.

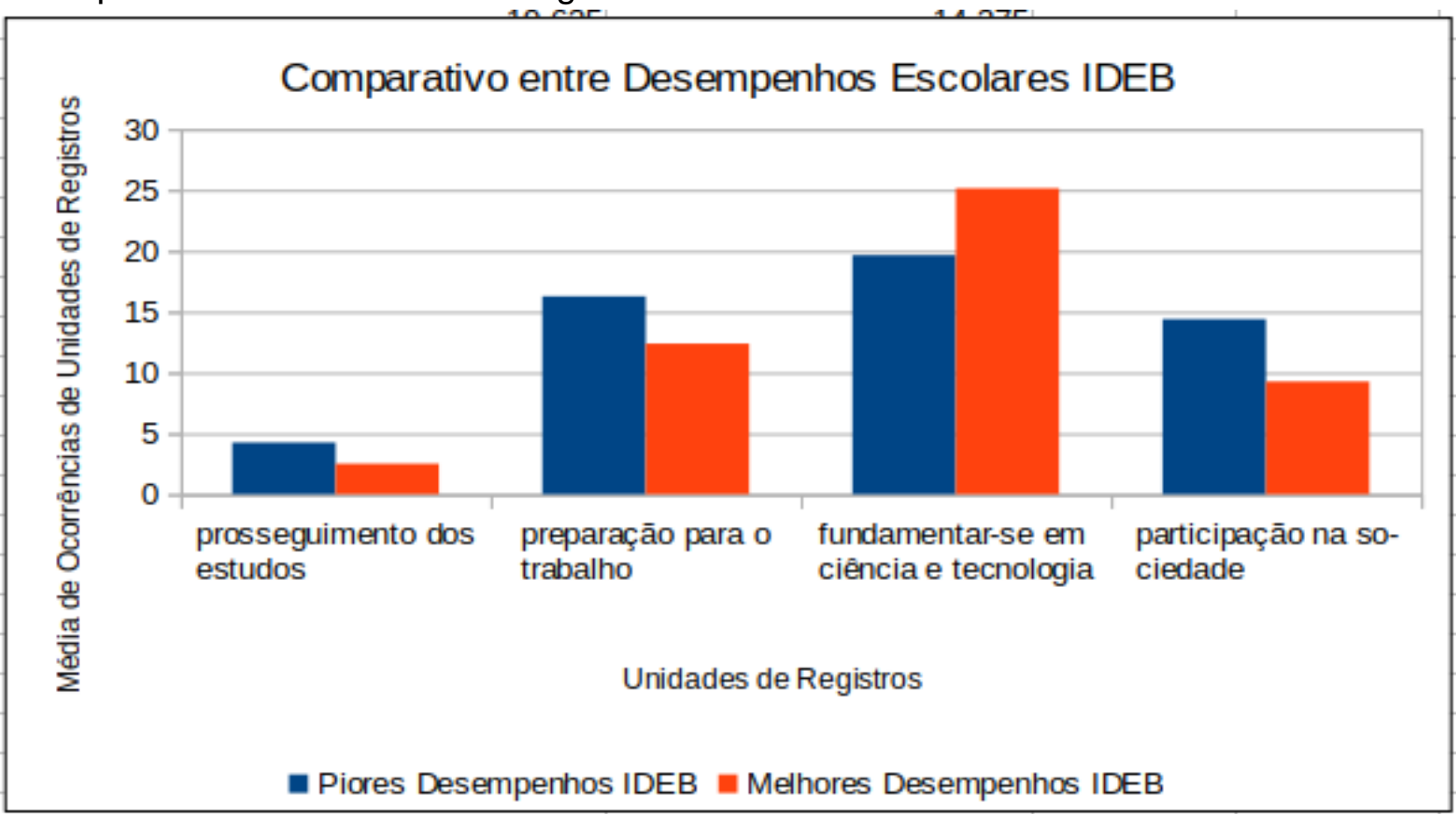

Fonte: autores.

Figura 7 -

Comparativo entre os Estados acerca do número de ocorrências do registro de unidade 'fundamentar-se em ciência e tecnologia'.

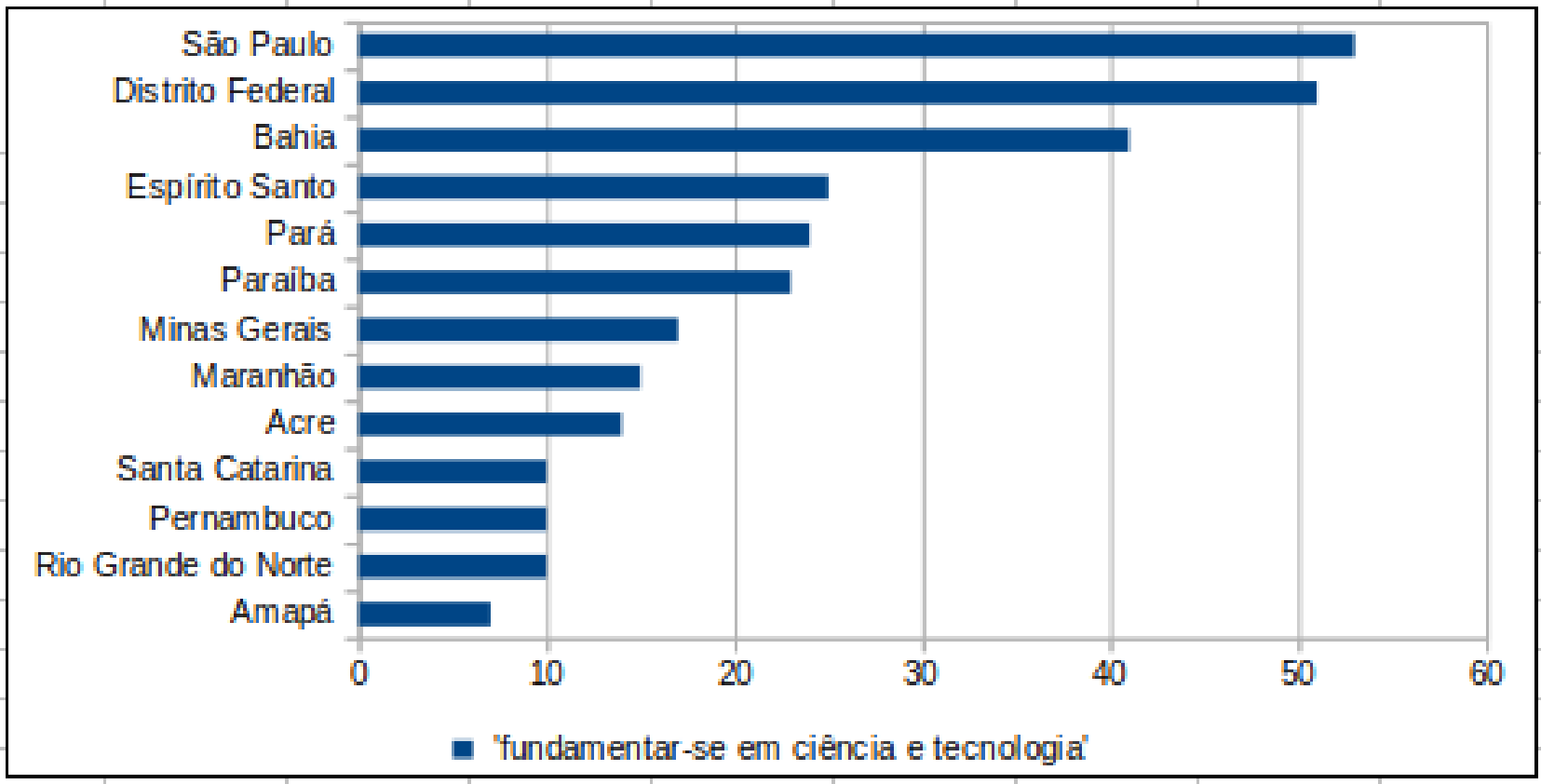

Fonte: autores. 
Para validar a 'preparação para o trabalho' do perfil idealizado nas bases legais foram contrapostos à frequência do registro de unidade e o percentual de pessoas na força de trabalho potencial, na população de 14 anos ou mais, e fora do mundo de trabalho (IBGE, 2019), ou taxa de desemprego, de cada uma das 13 unidades territoriais.

Objetivando compreender a formação para 'continuidade dos estudos' que compõe o perfil idealizado pelas bases legais do processo de formação no ensino médio foi feita a acareação desta e as matrículas no ensino superior considerando a soma dos ingressos na graduação de jovens com menos de 18 anos e os de 18 anos, provavelmente os recém-egressos do ensino médio.

Figura 8 -

Número de ocorrências dos registros de unidades nas bases legais.

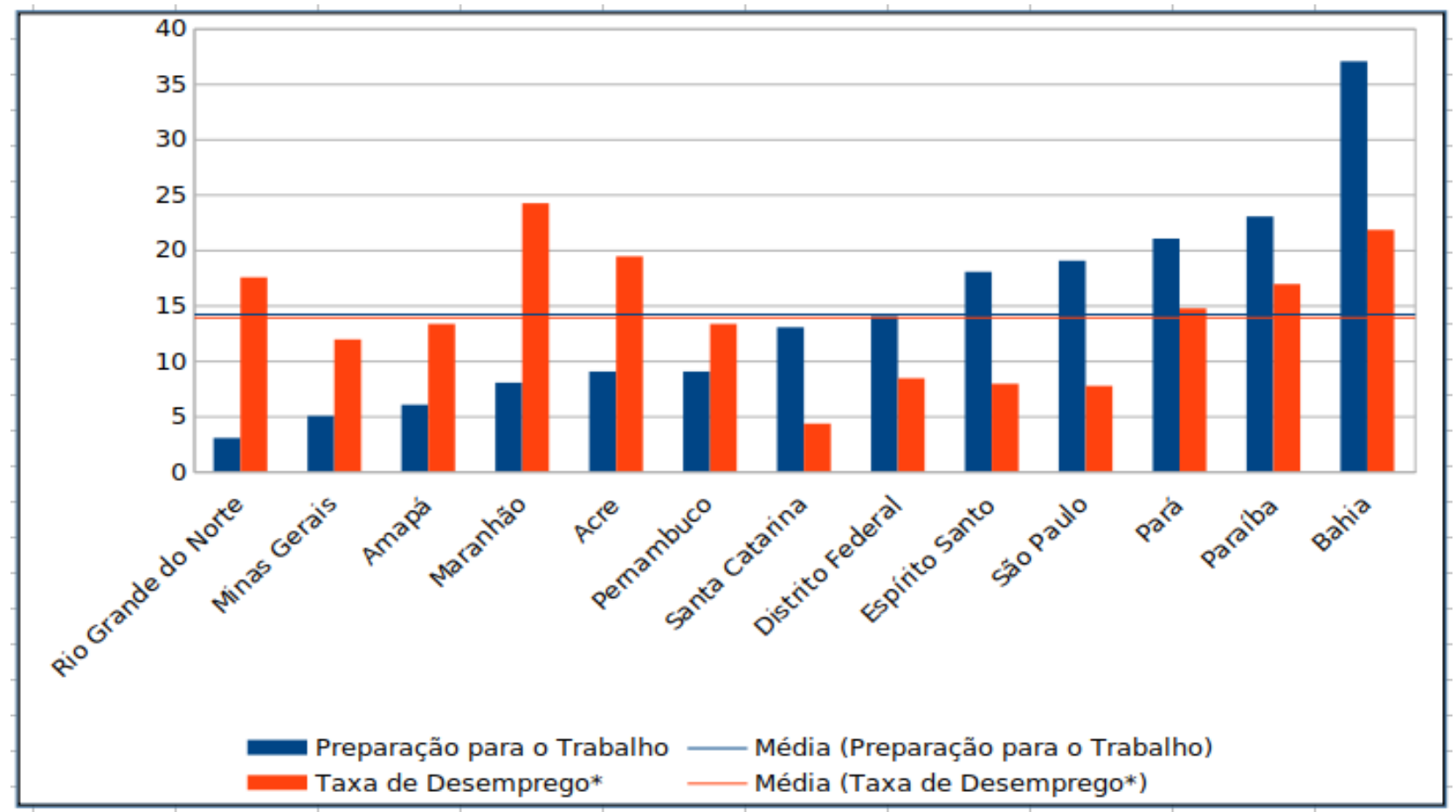

Fonte: autores.

Figura 9 -

Comparativo entre 'continuidade de estudos' e matrícula na graduação.

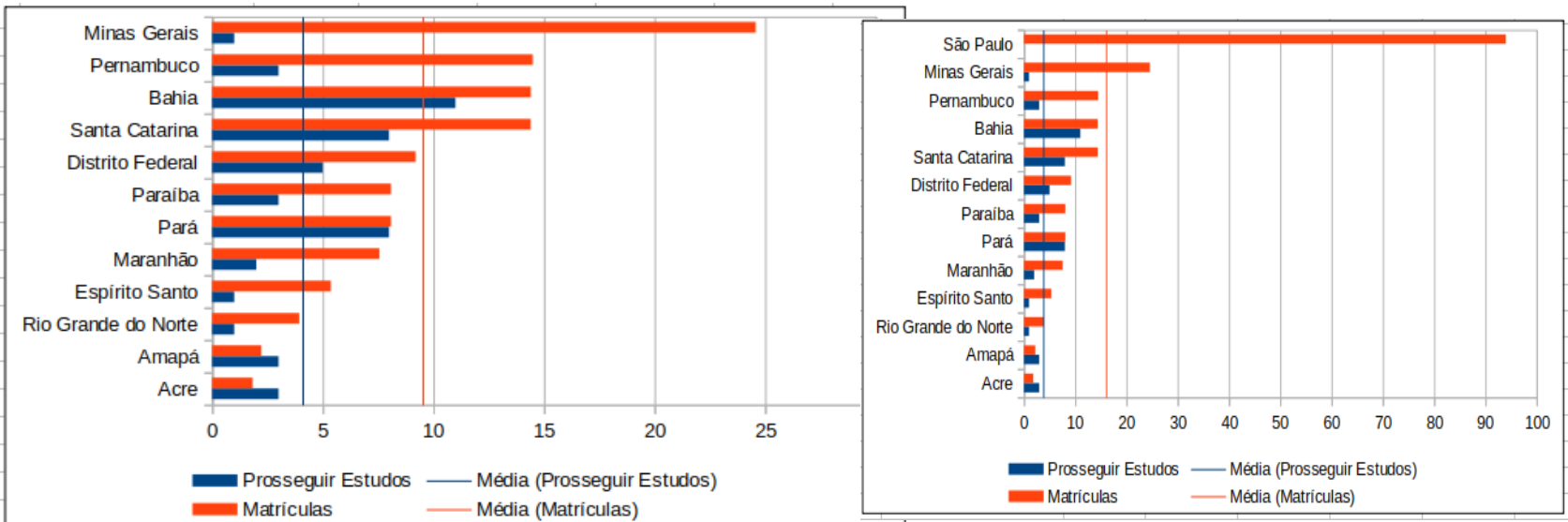

Fonte: autores. 
Vale destacar que foi necessário desconsiderar os dados do Estado de São Paulo, uma vez que não apresentou nenhuma referência à continuidade dos estudos em suas diretrizes estaduais e apresentou número de matrícula 90 vezes maior que o Estado com menor frequência de matriculados e, aproximadamente, cinco vezes maior que o Estado com segunda maior frequência.

Ao se tratar de 'participação na sociedade' nas bases legais consta que esta facilita a escolha da profissão. Assim, é válido acarear os Estados que se destacam neste tema e o número de concluintes na graduação. Foi necessário desconsiderar os dados de SP e MG, uma vez que apresentam, respectiva e aproximadamente, número de concluintes 66 e 26 vezes maior que o Estado com menor frequência de egressos da graduação e 5 e 2 vezes maior que o Estado com terceira maior frequência o que dificultaria o uso da média como parâmetro.

Figura 10 -

Comparativo entre 'participação na sociedade' e recém-graduados.

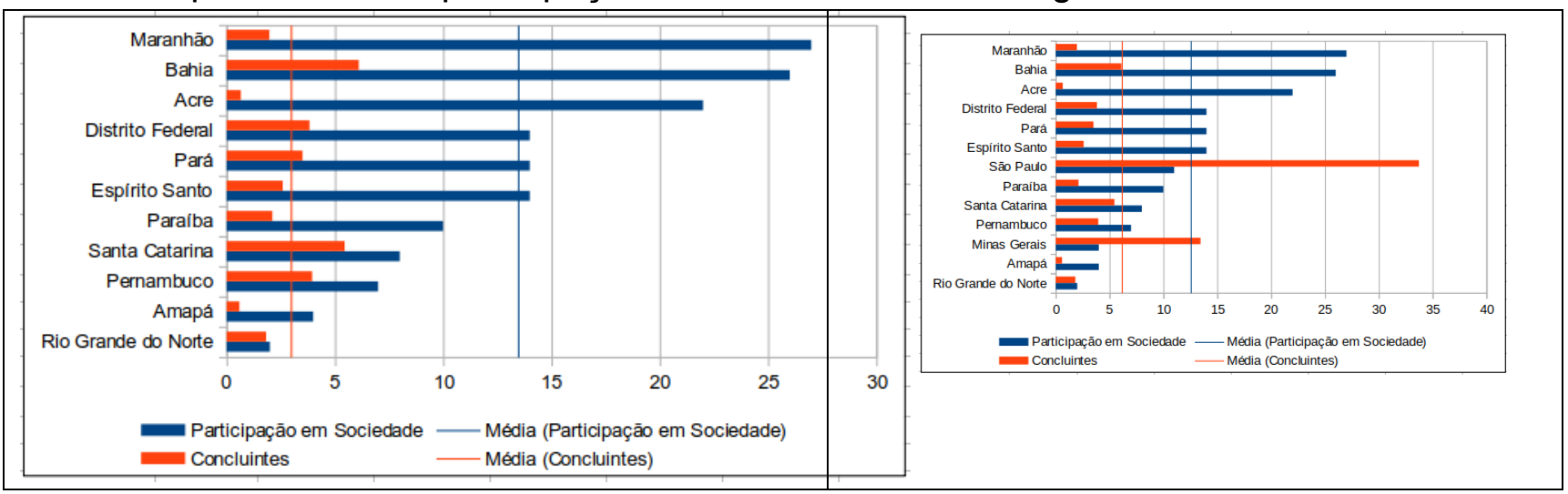

Fonte: autores.

\section{Discussão}

Nesta seção serão abordados cada um dos quatro registros de unidade, contrapondo os resultados da análise de conteúdo das bases legais, bem como argumentos contidos nestas e indicadores de monitoramento de qualidade de educação, desemprego, matrícula e conclusão do ensino superior.

Da acareação dos Estados com piores desempenho no Ideb e os de melhores desempenho observa-se que os currículos dos de melhor desempenho, em comparação com os outros três registros de unidade considerados, apresentam mais ocorrências de 'fundamentação científico-tecnológica', o que é explorado expressamente pelo sistema de avaliação a partir do qual este índice é definido. Apesar da necessidade de melhorias, uma vez que dos quatro Estados com melhores desempenho nas escolas públicas nenhum alcançou a meta projetada para o Brasil, para 2021, que é 6 no Ideb.

Os Estados cujas escolas apresentam melhor desempenho Ideb (Inep 2019) são: ES, PE, RN, SP, MG, DF e SC. E sobre o assunto, por exemplo, são ressaltadas, pelas orientações curriculares das unidades federativas, a necessidade de garantir ao estudante do Ensino Médio adequada apropriação das ciências como qualificação pessoal (São 
Paulo, 2000), acesso ao patrimônio científico acumulado pela humanidade (Pernambuco, 2012), e currículo implementado numa perspectiva científica que favoreça a construção do conhecimento escolar e científico (Distrito Federal, 2013).

Em contrapartida, na matriz de referência, composta pelos constructos para elaboração das provas componentes do Saeb (Inep, 2019), consta em Ciências Humanas, "razões e os processos pelos quais a sociedade busca conhecer, explorar e alterar recursos naturais, além de prever e prevenir catástrofes ambientais por meio da ciência e da tecnologia" e em Ciências da Natureza "os níveis de organização dos seres vivos e os critérios adotados pela ciência para sua classificação e agrupamento", sinalizando o foco Ideb em Ciências e Tecnologias.

Assim, a partir da análise do comparativo do desempenho Ideb em relação aos temas em estudo reforçam-se as evidências de que o 'fundamentar-se em ciência e tecnologia' é componente do perfil do egresso do ensino médio. Já analisando os Estados cujos currículos apresentam maior número de ocorrências neste tema: SP, DF, BA, ES, PA, PB e MG e notando que quatro deles - SP, DF, ES e MG - estão listados como unidades territoriais cujas escolas apresentam melhor desempenho Ideb, conclui-se também que este é objetivo que deve ser preservado nos currículos de ensino básico, pois tem reflexos na sociedade, no tocante à qualidade da educação.

Assim, considerando que a quantidade de ocorrências do registro de unidade 'preparação para o trabalho' nas orientações curriculares estaduais sinaliza a valorização, pelo respectivo Estado, de habilitar o estudante para conquistar uma ocupação no mundo do trabalho, da análise da contraposição entre as taxas de desemprego e a frequência em que os Estados da amostra espera-se uma relação inversamente proporcional entre os itens acareados.

Os Estados cujos currículos apresentam número de ocorrência deste registro de unidade acima da média dos outros Estados devem apresentar percentual de desempregados abaixo da média de desemprego: DF, ES, SP e PA. Já os Estados cujas orientações curriculares apresentam frequência de alinhamento com o trabalho, abaixo da respectiva média, devem apresentar número de desempregados acima da média de desemprego - RN, MA e AC - desconsiderando as condições de absorção para o trabalho.

Sobre o tema, nas diretrizes curriculares do DF, consta:

O princípio educativo do trabalho leva-nos a compreendê-lo como todas as formas de ação que os seres humanos desenvolvem para construir as condições que asseguram sua sobrevivência. Implica reconhecê-lo como responsável pela formação humana e pela constituição da sociedade. (Distrito Federal, 2013, p. 17)

Na proposta curricular do Estado de São Paulo há capítulo intitulado Princípio para um currículo comprometido com o seu tempo, no qual se destaca a articulação com o Mundo do Trabalho, onde consta:

Em síntese, a prioridade do trabalho na educação básica assume dois sentidos complementares: como valor, que imprime importância ao trabalho e cultiva o respeito que lhe é devido na sociedade, e como tema que perpassa os conteúdos curriculares, atribuindo sentido aos conhecimentos específicos das disciplinas. (São Paulo, 2000, p. 19) 
Ainda na análise da relação da taxa de desemprego e preparação para o trabalho os Estados de SC, MG, AP e PE, apesar de não atenderem à regra quanto às citadas médias, atendem à proporcionalidade invertida esperada: SC tem um preparo para 0 trabalho próximo à média e a menor taxa de desemprego, enquanto MG, AP e PE têm o $2^{\circ}, 3^{\circ}$ e o $6^{\circ}$ pior preparo para o trabalho, e taxas de desemprego próximas à média.

Já PB e BA contrariam a regra de proporcionalidade invertida, pois apresentam número de desempregados acima da média de desemprego, apesar de seus currículos valorizarem, também acima da respectiva média da amostra, a preparação para o trabalho. Em síntese, são Estados que menos valorizam o preparo para o trabalho - RN, MG, AP, MA, AC e PE - e contam com alta taxa de desemprego. Os Estados de SC, DF, ES, SP, PA, PB e BA valorizam o preparo para o trabalho, mas apenas os quatro primeiros contam com baixas taxas de desemprego, enquanto PB e BA apresentam números de desempregados acima da respectiva média.

Desta forma, cinco dos 13 Estados apresentam relação entre preparo para o trabalho e taxa de desemprego que sinalizam que a 'preparação para o trabalho' não constitui o perfil da maioria dos concluintes do ensino médio do país, pois apenas DF, ES, SP, PA e SC apresentam relação positiva neste quesito. Por outro lado, a análise dos dados de onze dos 13 Estados confirma a relação invertida entre 'preparação para o trabalho' e desemprego, o que reforça a necessidade dos currículos preservarem o zelo por este objetivo, porque desta forma são oportunizados impactos, possivelmente positivos, na sociedade quanto à empregabilidade.

\section{Continuidade dos estudos}

Ao mesmo tempo, segundo as disposições gerais da LDB, art. 22, a educação básica tem por finalidade desenvolver o estudante, assegurar-Ihe a formação comum indispensável para o exercício da cidadania e fornecer-lhe meios para progredir no trabalho e em estudos posteriores. Assim, para validar este aspecto do perfil do egresso do ensino médio foi efetuada a contraposição entre a quantidade de ocorrências do tema 'continuidade dos estudos' nas orientações curriculares das unidades territoriais do país e o número de matrículas na graduação, esperando-se uma relação diretamente proporcional. Os Estados da amostra em que esta relação é positiva, ou seja, aqueles com número de ocorrências do tema nos currículos estaduais acima da respectiva média, e que têm número de matrícula no ensino superior acima da média de matriculados na graduação são: BA, SC e DF.

Sobre o tema, nas orientações estaduais consta que o ensino médio "foi marcado por uma dupla perspectiva: de um lado, a ênfase na formação para o trabalho; e, de outro, a ênfase na continuidade dos estudos no nível da educação superior" (Bahia, 2015, p. 30 ), tem "prática pedagógica pautada em necessidades reais de jovens que frequentam as escolas públicas brasileiras... necessidades que vão desde a formação para o mundo do trabalho e/ou para a continuidade dos estudos" (Distrito Federal, 2013, p. 72).

$\mathrm{PB}, \mathrm{MA}, \mathrm{ES}, \mathrm{RN}, \mathrm{AP}$ e $\mathrm{AC}$ são Estados que, apesar de confirmarem a regra de proporcionalidade direta, apresentam relação negativa - o número de registros de unidade nos respectivos currículos estaduais está abaixo da média de ocorrências destas nos Estados da amostra -, e têm também o número de matrícula no ensino superior abaixo da média de matriculados nas unidades territoriais em estudo. 
Contrariam a regra apresentando relação inversamente proporcional MG, PE, mas com resultados positivos, ou seja, altos números de matrícula no ensino superior, mais precisamente $1^{\circ}$ e $2^{\circ}$ lugar no ranking dos Estados da amostra, neste quesito. As diretrizes curriculares estaduais de MG, ao tratar sobre as DCN - Ensino Médio, conclui que "a lei sinaliza assim que, mesmo a preparação para o prosseguimento de estudos, terá como conteúdo não o acúmulo de informações, mas a continuação do desenvolvimento da capacidade de aprender e a compreensão do mundo físico, social e cultural" (Minas Gerais, 2008, p. 12).

Já DF e PA não cumprem a regra por completo, mas aproximam-se desta e com relação positiva. O currículo do DF dá importância acima da média à continuidade dos estudos e tem matrícula no ensino superior próximo à respectiva média. E o Pará apresenta as grandezas em análise nas mesmas proporções, sinalizando relação diretamente proporcional também.

Assim, tem-se resultados positivos em BA, SC, DF, MG, PE, DF e PA, ou seja, sete dos 13 Estados, sinalizando que estímulo ao prosseguimento dos estudos é componente do perfil do egresso do Ensino médio. E ainda, dada a constatação do cumprimento da relação diretamente proporcional em 11 dos Estados estudados, é válido manter este objetivo dos currículos e em iniciativas de educação do Ensino Médio, porque desta forma, impactos positivos acerca de acesso ao ensino superior, com efeitos sobre a sociedade podem ser obtidos.

\section{Participação em sociedade}

Nas bases legais consideradas consta que a 'participação em sociedade' facilita a escolha da profissão e o vínculo com o mundo do trabalho. Assim, espera-se uma relação diretamente proporcional entre a frequência de 'participação em sociedade' nas diretrizes curriculares estaduais e o número de respectivos concluintes nos Estados em análise, em relação às respectivas médias. Observa-se que BA, DF e PA apresentam números de ocorrências do tema maior que a respectiva média, bem como número de concluintes maior que a médias das conclusões - relação diretamente proporcional positiva.

Os Estados de PB, AP e RN apresentam relação diretamente proporcional em relação à média, porém negativa: o número de ocorrências da unidade de registro, bem como o de concluintes são menores que a média.

PE, SC, SP, MG, MA, AC e ES apresentam relação inversa, diferente do esperado. Nos quatro primeiros - PE, SC, SP e MG - o número de concluintes é acima da média dos Estados em estudo, mas a quantidade de ocorrências do tema nos currículos encontra-se abaixo da respectiva média. Já em MA, AC e ES ocorre o contrário - o número de concluintes é abaixo da média de conclusão no ensino superior e a frequência do registro de unidade localizada nas respectivas diretrizes curriculares é acima da respectiva média.

Sobre o tema, nas diretrizes curriculares estaduais, consta que: este currículo "procura integrar saberes que situem, de forma crítica e transformadora, o estudante em seu tempo e lugar, desenvolvendo o seu protagonismo como sujeitos sociais imersos e comprometidos com o presente, bem como com o seu futuro profissional e com o futuro da coletividade" (Bahia, 2015, p. 12), e na EJA: "jovens, adultos e idosos terão 
oportunidades de atualizar conhecimentos, trocar experiências, participar de práticas sociais e culturais, aprofundar estudos e ter acesso a novas dimensões do mundo do trabalho e da cultura" (Pernambuco, 2012, p. 59).

Em resumo sobre 'participação em sociedade' apresentam resultados positivos BA, $D F, P A, M A, A C$ e ES, dos quais três não apresentam correspondência com a quantidade de formandos no ensino superior, logo para a maioria dos egressos do ensino médio, a participação em sociedade precisa ser melhor trabalhada. Também a relação de proporcionalidade direta com a conclusão da graduação não foi confirmada na maioria dos Estados da amostra, logo é um tema que requer mais estudos.

\section{Considerações finais}

O perfil idealizado pelas bases legais de educação para o egresso do processo de formação no ensino médio é composto por 'prosseguimento dos estudos', 'preparação para o trabalho', 'fundamentar-se na ciência e na tecnologia' e 'participação em sociedade'. Mas contrapondo com os indicadores de monitoramento do ensino, de empregabilidade, de ingresso e conclusão no ensino superior notam-se sinais de que apenas o 'prosseguimento dos estudos' e a 'fundamentação científico-tecnológica' são componentes do perfil de conclusão do nível de ensino em estudo.

Também considerando os impactos na sociedade - relativos à matrícula no ensino superior, empregabilidade e qualidade da educação - observados a partir das conclusões das análises dos registros de unidade selecionados, vale manter nos currículos 'prosseguimento dos estudos', 'preparação para o trabalho', 'fundamentar-se na ciência e na tecnologia' não apenas para cumprir determinação previstas na legislação educacional, mas também por atender aos interesses e necessidades dos estudantes e da sociedade. Quanto à 'participação em sociedade' é preciso ser mais amplamente estudada de forma a possibilitar melhor compreensão da interação efetiva desta com os outros elementos do currículo, e de como inseri-la no espaço e tempo escolar.

\section{Referências}

ACRE. Orientações curriculares para o ensino médio do estado do Acre. Rio Branco: Governo do Estado, 2017.

ADEYEMI, Adeyemi. Content analysis of civic education curriculum in senior secondary schools in Osun State, Nigeria. Educational Research and Reviews, Regensburg, v. 13, n. 2, 2018, p. 464-471.

AMAPÁ. Plano estadual de educação do Amapá 2015/2016. Macapá: Governo do Estado, 2015.

ARIFAH, Kurnia Fitri; SANTOSA Riyadi; NGADISO. Content analysis of competences and scientific approach in english textbook. International Journal of Multicultural and Multireligious Understanding, Hamburg, v. 5, n. 3, 2018, p. 219-233.

BAHIA. Orientações curriculares para o ensino médio do Estado da Bahia. Salvador: Governo do Estado, 2015.

BARDIN, L. Análise de conteúdo. São Paulo: Edições 70, 2016.

BRASIL. Lei de diretrizes e bases da educação. Brasília: DOU, 1996. 
COMER, Leighoa. Content analysis of chronic pain content at three undergraduate medical schools in Ontario, Canadian Journal of Pain, Toronto v. 1, 1, 2017, p. 75-83.

DIRLIKHI, Murat; AYDIN Kamil; AKGÜN, Levent. Cooperative learning in Turkey: a content analysis of theses. Educational Sciences: Theory \& Practice, JCF Corp, Londres, v. 16, n. 4, 2016, p. 1251-1273.

DISTRITO FEDERAL. Currículo em movimento do ensino médio do Distrito Federal. Brasília: Secretaria do Estado da Educação, 2013.

ESPÍRITO SANTO. Currículo básico do ensino médio do Espírito Santo. Vitória: Secretaria de Estado da Educação, 2009.

IBGE. PNAD contínua trimestral. Rio de Janeiro: IBGE, 2019.

INEP. Índice de desenvolvimento da educação básica - 3o ano - ensino médio. Brasília: Inep, 2017.

INEP. Sinopse estatística da educação superior 2018. Brasília: Inep, 2019.

MARANHÃO. Orientações curriculares para o ensino médio do estado do Maranhão. São Luís: Governo do Estado, 2017.

MEC. Base nacional comum curricular - ensino médio. Brasília: MEC/Secretaria de Educação Básica, 2017.

MEC. Diretrizes curriculares nacionais gerais para a educação básica. Brasília: MEC, 2010.

MEC. Diretrizes curriculares nacionais para o ensino médio. Brasília: MEC, 2012.

MEC. Parâmetros nacionais de qualidade para a educação infantil. Brasília: MEC, 2006.

MINAS GERAIS. Conteúdo básico comum do ensino médio do estado de Minas Gerais. Belo Horizonte: Secretaria de Estado da Educação, 2008.

OECD. Education at a glance 2019: OECD indicators. Paris: OECD, 2019.

PARÁ. Base do plano estadual de educação do estado do Pará. Belém: Governo do Estado, 2010.

PARAíBA. Plano estadual de educação da Paraíba. João Pessoa: Governo do Estado, 2006.

PERNAMBUCO. Parâmetros para a educação básica do estado de Pernambuco. Recife: Governo do Estado, 2012.

RIO GRANDE DO NORTE. Plano estadual de educação do Rio Grande do Norte. Natal: Governo do Estado, 2006.

SANTA CATARINA. Ensino médio noturno em Santa Catarina: democratização e diversidade. Florianópolis: Governo do Estado, 2008.

SÃO PAULO. Proposta curricular do estado de São Paulo. São Paulo: Governo do Estado, 2000.

Kenia Kodel Cox é professora na Universidade Federal de Sergipe.

Orcid: http://orcid.org/0000-0002-0261-4618.

Endereço: Rua C, 600, Conj. Eduardo Gomes - 49100-000 - São Cristóvão - SE -

Brasil.

E-mail: kenia@dcomp.ufs.br. 
Robelius De-Bortoli é professor na Universidade Federal de Sergipe.

Orcid: http://orcid.org/0000-0003-1231-6451.

Endereço: Avenida Melício Machado, 1440, casa 33 - 49038-443 - Aracaju - SE Brasil.

E-mail: robelius@yahoo.com.br.

Critérios de autoria: todos os autores conceberam a ideia. Kenia Kodel coletou os dados, os analisou e preparou a primeira versão. Robelius De-Bortolli revisou o trabalho efetuado por Kenia Kodel. Ambos discutiram os resultados e contribuíram para a versão final do manuscrito.

Recebido em 15 de dezembro de 2020.

Aceito em 9 de maio de 2021.

cc) (i) (s) $\Theta$ 